\title{
Comparison of individuals with low versus high consumption of home-prepared food in a group with universally high dietary quality: a cross-sectional analysis of the UK National Diet \& Nutrition Survey (2008-2016)
}

\author{
Chloe Clifford Astbury *i( ), Tarra L. Penney and Jean Adams
}

\begin{abstract}
Background: Despite inconclusive evidence, the idea that a lack of home food preparation and skills is a limiting factor in achieving a healthy diet is widespread. Cooking skills interventions proliferate, and several countries now mention cooking in their dietary guidelines. The aim of this study was to determine whether substantial consumption of home-prepared food is necessary for high dietary quality by exploring whether individuals can eat healthily while eating little home-prepared food. The diets of these individuals were characterised, and sociodemographic characteristics and prevalence of obesity were also explored.

Methods: Cross-sectional analysis of UK dietary survey data with objectively measured height and weight and a 4-day food diary for each participant was conducted. A subsample ( $N=1063$, aged $\geq 19$ years) with a high dietary quality (determined using a score derived from the Dietary Approaches to Stopping Hypertension (DASH) diet) was analysed. Within this, participants were grouped as either high or low home preparation based on the proportion of energy derived from home-prepared food. Regression models were used to determine whether and how those in the high and low home preparation groups differed in terms of socio-demographic characteristics, DASH score, energy intake, prevalence of obesity, and dietary composition.

Results: The low home preparation group included 442 participants, while 621 participants were in the high home preparation group. The low home preparation group were more likely to be older and white, and less likely to have a degree level education. After adjustment for socio-demographic characteristics, there were no differences in DASH score, energy intake or obesity prevalence between the groups. After adjustment, the low home preparation group consumed more fruit (30.8 additional g/day, 95\% Cl 5.5-56.1), more low-fat dairy foods (24.6 additional g/day, 95\% Cl 1.7-47.5) and less red meat (10.4 fewer g/day, 95\% Cl 4.3-16.6), but also more sugar (11.6 additional g/day, 95\% Cl 7.5-15.6) and sodium (107.8 additional mg/day, 95\% Cl 13.8-201.8).

Conclusion: Home food preparation should not be presented as a prerequisite to a high quality diet. The public health community should recognise the existence of a set of food practices which allows individuals to achieve a healthy diet with little contribution from home-prepared food, and make space for it in the design of their policies and interventions.
\end{abstract}

Keywords: Home-prepared food, Food practices, Cooking, Cooking skills, Food skills, DASH, Diet quality

\footnotetext{
* Correspondence: cc713@medschl.cam.ac.uk

MRC Epidemiology Unit \& Centre for Diet and Activity Research (CEDAR),

University of Cambridge, Box 285, Institute of Metabolic Science, Cambridge

Biomedical Campus, Cambridge CB2 0QQ, UK
}

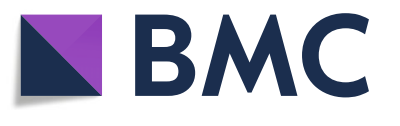

(c) The Author(s). 2019 Open Access This article is distributed under the terms of the Creative Commons Attribution 4.0 International License (http://creativecommons.org/licenses/by/4.0/), which permits unrestricted use, distribution, and reproduction in any medium, provided you give appropriate credit to the original author(s) and the source, provide a link to the Creative Commons license, and indicate if changes were made. The Creative Commons Public Domain Dedication waiver (http://creativecommons.org/publicdomain/zero/1.0/) applies to the data made available in this article, unless otherwise stated. 


\section{Background}

Given the significant contribution of diet to the ever-growing burden of chronic disease, [1] and the potential role a healthy diet could have in preventing overweight and obesity, heart disease, cancer and diabetes, [2-6] improving dietary quality at the population level emerges as one of the most urgent tasks for public health.

The rise in diet-related disease arrives in tandem with an increase in the consumption of food prepared outside the home [7, 8]. A decrease in time spent cooking at home has also been observed in most high-income countries, $[9,10]$ though there is evidence from the United States that the latter trend has been reversed since the early 2000s [11]. The consumption of food prepared outside the home is known to be associated with harmful dietary behaviours and negative health outcomes [12-14]. In contrast, there is some evidence, albeit less consistent, to suggest that higher frequency of both cooking [15-19] and eating home-prepared meals [20] is associated with better dietary intake and improved health outcomes.

There is significant interest from academics and policymakers in understanding the modifiable determinants of both these behaviours, and seeking ways of promoting the consumption of home-prepared food [21-24]. Countries such as Brazil [25] and Japan [26] have included cooking and food and cooking skills in their dietary guidelines, while Canada's revised food guide will emphasise building food-related 'skills and knowledge' in its population as a means of improving dietary quality [27].

Further downstream, cooking and food classes and workshops are a popular public health intervention, and a wide variety of models run by governmental bodies, charities and social enterprises proliferate in countries such as the UK, the US, and Australia [28-30]. These interventions target a number of different demographics, and include a variety of components, including cooking workshops but also supermarket visits, nutrition classes, tasting sessions and work in kitchen gardens, deployed singly or in combination.

However, evidence of the effectiveness of these interventions is equivocal: systematic reviews conclude that evidence of significant and lasting change in either dietary behaviours or related health outcomes is limited [28-30]. Authors suggest this may in part be due to limitations in the design of both the interventions and their evaluations, but nevertheless existing evidence suggests that getting people to cook more or differently is difficult. With this in mind, it seems reasonable to pose the question: is substantial consumption of home-prepared food necessary for a healthy diet?

Promoting home cooking as a dietary public health intervention is based on the hypothesis that people who cook more have healthier diets and better health outcomes, an idea supported by some, [15-20] though admittedly not all, [31-34] of the evidence. However, preparing and eating food at home is complex, and the nutritional content of home-prepared meals can be highly variable, as can the nutritional content of meals prepared outside the home. One study showed that popular ready meals came closer to meeting dietary guidelines than homemade equivalents made using recipes from television chefs (though neither met the guidelines under study) [32]. Another study reported no significant difference between the healthfulness of ready meals and meals made at home using recipes from popular online sources and cookery books [35]. In a longitudinal, multi-ethnic study of midlife women, women who spent more time on meal preparation were more likely to develop metabolic syndrome, leading the authors to conclude that public health interventions should emphasise healthfulness of cooking as opposed to just cooking frequency [31].

Though there is some evidence that eating more home-prepared food is associated with better dietary quality, [20] the association between eating home-prepared food and dietary quality may be heterogeneous depending on what exactly is eaten.

An earlier (recently replaced) version of France's Guides alimentaires du programme national nutritionsanté (national dietary guidelines) [36] proposed recommendations for different types of eaters, including for individuals who 'do not cook'. Suggestions included bread and cereals, salad, fruit, milk and cheese. This seems to reflect a belief that it is possible to achieve a high quality diet while eating food that requires little or no home preparation. To the best of our knowledge, this hypothesis has not been quantitatively examined.

The aims of this study were (1) to determine whether substantial consumption of home-prepared food is for high dietary quality by exploring whether individuals can achieve a relatively high quality of diet while obtaining a relatively low proportion of their energy from home-prepared food; and (2) to characterise the diets of these individuals, if found, relative to their counterparts who also achieved a high quality diet while consuming a relatively large proportion of energy from home-prepared food. Individual-level socioeconomic and demographic characteristics of the two groups were also compared, as well as prevalence of overweight or obesity.

\section{Methods}

This study represents a cross-sectional analysis of dietary surveillance data from the UK National Diet and Nutrition Survey (NDNS) 2008-16 (May 2018 release) [37]. It is reported according to the STROBE-nut recommendations [38]. 


\section{Data source}

NDNS is an annual cross-sectional survey which collects information on food consumption and nutritional and health status of free-living individuals in the UK. Sampling, recruitment and data collection are carried out in a consistent manner, allowing data from different survey years to be combined for cross-sectional analysis.

A detailed account of the NDNS recruitment and sampling protocol has been published elsewhere [39-41]. In short, private addresses were randomly selected from postcode sectors across the UK. Within each household, a maximum of one adult and one child were randomly selected for inclusion in the study. These individuals were asked to complete a four-day food and drink diary, and to participate in an interview concerning more general dietary habits, socio-demographic status, lifestyle and physical activity, and receive a nurse visit which included measurement of height and weight.

NDNS was approved by the Oxfordshire Research Ethics Committee and written informed consent was obtained from all participants.

\section{Inclusion criteria}

Individuals aged $\geq 19$ years at the time of participation, who completed three or four days of the food diary, were included in the analyses. In order to compare those who achieved a relatively high dietary quality with and without a relatively high proportion of energy from home-cooked foods, only a sub-sample of the NDNS sample (the analytic sample) was included in this analysis: those in the top tertiles of both proportion of energy from home-prepared food and dietary quality (hereafter the high home preparation group), and those in the top tertile of dietary quality and the bottom tertile of energy from home-prepared food (the low home preparation group). This resulted in an analytic sample with universally high dietary quality, allowing inter-group differences to be associated with consumption of home-prepared food as opposed to dietary quality.

\section{Dietary assessment}

Participants completed unweighed food diaries, including all food and beverages consumed both inside and outside the home for three or four consecutive days. This process is described in detail elsewhere [42]. Participants also recorded where the food was eaten, for example at home, in a restaurant or café, or at work. This variable included a specific category for food eaten at work but brought from home.

\section{Characterisation of food-related variables}

Food-related variables - proportion of home-prepared food and dietary quality, as well as other aspects of diet such as daily intake of food groups, energy and macroand micronutrients - were derived from food diaries.
The first two variables were derived in order to classify participants as being either in the high or low home preparation group. Further food-related variables were derived in order to characterise dietary intake in greater detail.

\section{Proportion of energy from home-prepared food}

Food items listed in food diaries were classified by the authors as either requiring or not requiring home preparation. All foods were classified as home-prepared except those listed in Table 1. Foods which should not be classified as being home-prepared were decided by the authors a priori.

Definitions of 'cooking' have been discussed extensively and remain contested $[21,43,44]$, with many definitions not deeming the application of heat to be a necessary part of this process $[44,45]$. As a result 'home food preparation' and 'home-prepared food' seem more accurate and are the concepts deployed here. Different, but related, conceptualisations exist, such as food 'prepared from scratch' [46], or food that is not 'from outside the home' [7]. The conceptualisation of homeprepared food used here reflects several conceptions of 'cooking', or home food preparation, drawn from qualitative studies $[47,48]$ as well as behaviours which are habitually enquired about in studies of 'cooking', such as blending, mixing, boiling, chopping, roasting and pan frying [49]. From this conceptualisation of home food preparation, a set of behaviours, we defined foods which we would deem to be home-prepared as being the products of these behaviours.

Food classification was carried out using food diary variables as illustrated in Fig. 1, with foods which were not classified as home-prepared being successively removed until only food included in home-prepared dishes remained. The proportion of energy from home-prepared food was then calculated for each participant by summing the energetic content of foods classified as home-prepared and dividing them by the participant's total energy intake. Participants were then separated into tertiles based on this proportion. Individuals in the highest tertile for

Table 1 Foods not classified as home-prepared

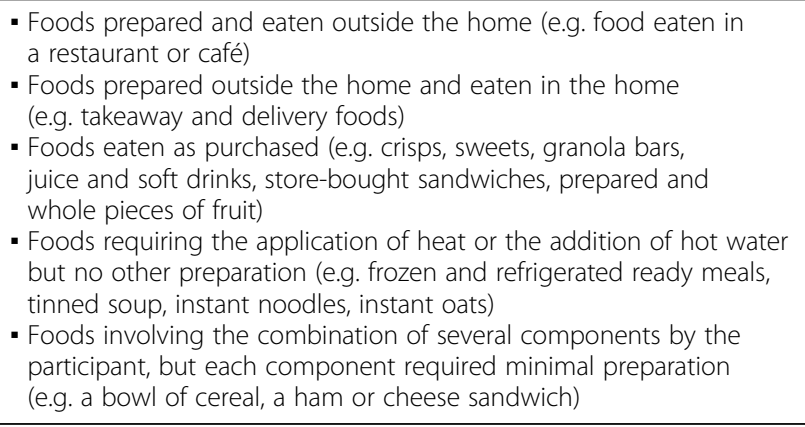




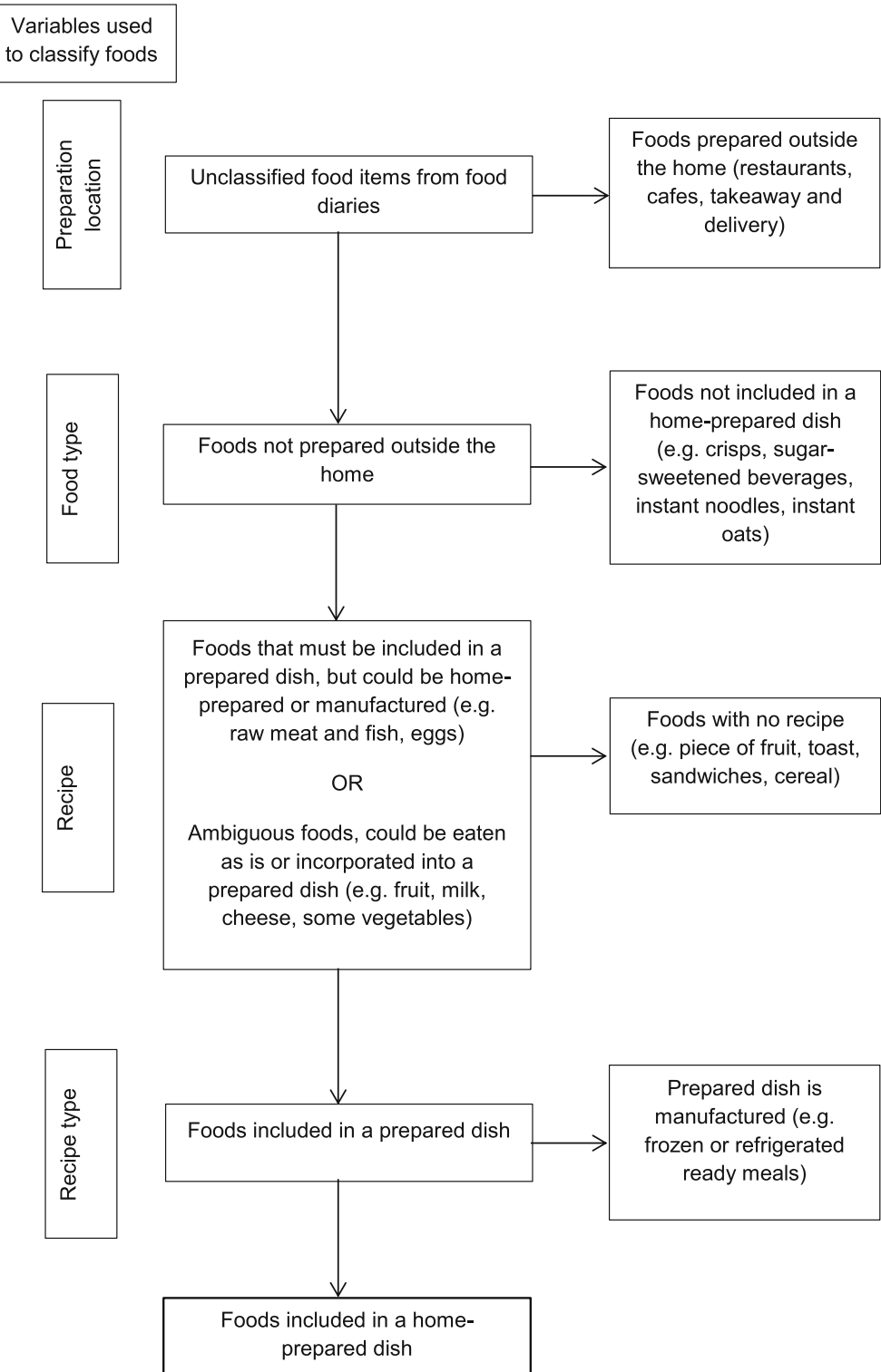

Fig. 1 Flow diagram for classification of foods as being home-prepared

proportion of energy from home-prepared foods were categorised as belonging to the high home preparation group, while those in the lowest tertile were categorised as belonging to the low home preparation group.

\section{Dietary quality}

Dietary quality was determined by quantifying accordance to the Dietary Approaches to Stopping Hypertension (DASH) dietary pattern using a method adapted for use with NDNS [50] from an existing index [51]. The DASH diet has been shown to lower blood pressure [52] and reduce low-density lipoprotein cholesterol levels, [52] as well as being associated with a lower risk of stroke and coronary heart disease [51]. This score is based on food and nutrients emphasised or minimised in the DASH diet, and has eight components: high intake of fruits, vegetables, nuts and legumes, low-fat dairy products, and whole grains; and low intake of sodium, red and processed meats, and non-extrinsic milk sugars; all adjusted for total energy intake. The score is adjusted for overall energy intake. Components are evenly weighted, and three components (sodium, sugar, and red and processed meats) are reverse-scored, so that higher consumption would lower an individual's DASH score.

Participants were separated into tertiles by DASH score. Participants in the highest tertile were categorised as high-DASH. 


\section{Intake of energy, macronutrients and micronutrients}

Mean daily intake of energy was estimated by the NDNS team using food diaries, as were daily intakes of several macro- and micronutrients: fat, saturated fat, protein, carbohydrate, sugar, and sodium, a process described in detail elsewhere [42]. These nutrients make up mandatory nutrition labelling in the UK [53]. Intake was categorised as meeting or not meeting relevant UK dietary guidelines, $[54,55]$ except in the case of carbohydrates. Current UK recommendations suggest a population mean of approximately $50 \%$ of total energy from carbohydrate, but note that total carbohydrate intake does not appear to be associated with health outcomes, as it is composed of different nutrients such as fibre, sugar and starches, which may have a variety of impacts [56]. Therefore, carbohydrate intake was described in all groups, but adherence to a particular recommendation was not defined.

Daily intakes of other nutrients were also estimated by the NDNS team using food diaries [42]. Where UK guidelines existed, [54] adherence to these guidelines was also determined. Nutrients included were: fibre, thiamine, riboflavin, niacin, vitamin $\mathrm{B} 6$, vitamin $\mathrm{B} 12$, folate, vitamin $C$, vitamin $A$, calcium, phosphorus, magnesium, zinc, selenium, iodine, iron, chloride, vitamin $\mathrm{E}$, copper, manganese, biotin, and pantothenic acid. Nutrients derived from supplements were not included in the data presented here.

\section{Intake of food groups}

Daily intakes of the main food groups determined by NDNS were calculated using food diaries. Where possible similar groups of food were collapsed (e.g. 1\% fat milk, skimmed milk and semi-skimmed milk).

\section{Prevalence of overweight and obesity}

Interviewers collected measurements of height and weight from NDNS participants using standard protocol. These measures were used to calculate BMI, which was categorised as overweight/obese (BMI $\geq 25 \mathrm{~kg} / \mathrm{m}^{2}$ ), or not.

\section{Socio-demographic variables}

Socio-demographic variables considered include age, sex and ethnicity (categorised as white or not due to the high proportion of white participants in NDNS) were determined using self-reported survey responses, as were the presence of a child under 16 years of age in participant households. Socioeconomic position was also assessed using self-reported survey responses, and was characterised using a range of markers: occupation (professional/other), education (degree level or above/other), and annual income equivalised for household composition (above or below £35,000).

\section{Analysis}

The demographic and socioeconomic characteristics of individuals in the high-home preparation and low home-preparation groups were described. The statistical significance of differences between groups was tested using either a linear or logistic regression as appropriate, mutually adjusted for all other socio-demographic variables.

Overall dietary characteristics were examined in two ways. First, the high home preparation and low home preparation groups were compared in terms of DASH score, proportion of energy from home-prepared food, energy intake, and adherence to dietary guidelines for macro- and micronutrients. Prevalence of overweight or obesity was also compared across groups. Second, the groups were compared in terms of their intake of each of the food groups or nutrients that make up each of the eight components of the DASH diet and index: low-fat dairy, whole grain, fruit, vegetables, nuts and legumes, sodium, sugars, and red and processed meats. In both cases, the statistical significance of differences between groups was tested using either a linear or logistic regression as appropriate, adjusted for all socio-demographic variables.

In addition, food-level differences between home preparation groups were then assessed through an examination of the food group codes provided by NDNS. Due to the high proportion of individuals who did not consume many of the food groups over the course of the recorded days, this was done in two steps. First, the proportion of individuals consuming any amount from each food groups was calculated for both the high home preparation and the low home preparation groups. Differences in these proportions were tested using logistic regression. Second, the median quantity of each food group consumed by consumers of those food groups was determined. Differences between home preparation groups in these quantities were tested using linear regression. All regressions in food-level analyses were adjusted for all socio-demographic variables.

All analyses were conducted using Stata (version 14; Stata Corp.). Alpha-level of 0.05 was used throughout.

\section{Results}

Overall, $54 \%(N=12,070)$ of individuals selected to take part in NDNS provided useable food diaries (three or four complete days), including 6364 adults [39, 40, 57]. Adult participants classified by tertile of DASH score and proportion of energy derived from home-prepared food are displayed in Table 2.

The analytic sample used in this study therefore included 1063 participants (16.7\% of adult NDNS sample): 621 (9.8\%) participants in the high home 
Table 2 Adult NDNS participants by tertile of DASH score and proportion of energy derived from home-prepared food $n$ (\% of adult study sample)

\begin{tabular}{lllll}
\hline DASH & \multicolumn{2}{l}{ Proportion of energy from home-prepared food } & Total \\
\cline { 2 - 4 } & Low & Medium & High & \\
\hline Low & $1095(17.2)$ & $836(13.1)$ & $679(10.7)$ & $2610(41.0)$ \\
Medium & $703(11.1)$ & $697(11.0)$ & $713(11.2)$ & $2113(33.2)$ \\
High & $442(7.0)$ & $578(9.1)$ & $621(9.8)$ & $1641(25.8)$ \\
Total & $2240(35.2)$ & $2111(33.2)$ & $2013(31.6)$ & $6364(100.0)$ \\
\hline
\end{tabular}

preparation group, and $442(7.0 \%)$ participants in the low home preparation group. While NDNS is a nationally representative sample, the analytic sample differs from the rest of the NDNS sample, notably in having a higher socioeconomic position, as well as being older, less likely to be male or white, and less likely to have a child aged under 16 living at home (Table 3 in Appendix).

Table 3 presents sample demographic and socioeconomic characteristics for individuals in the high and low home preparation groups. Table 4 shows that, after adjustment for all other sociodemographic variables, individuals in the low home preparation group were more likely to be older and white, and less likely to have a degree level education relative to the high home preparation group.

Table 4 presents an overview of dietary characteristics of those in the high and low home preparation groups. Table 4 shows that, after adjustment for socio-demographic characteristics, both groups achieved the same levels of DASH adherence, and showed no significant differences in their mean daily energy intake (kcal) or their prevalence of overweight and obesity, despite proportion of energy they derive from home-prepared food being substantially and significantly different. At a nutrient level, however, some differences emerged. In the low home preparation group, a smaller proportion of participants adhered to dietary guidelines for sugar and sodium; but there were no between-group differences in proportion adhering to guidelines on fat, saturated fat and protein.

Information about adherence to micronutrient guidelines can be found in Table 6 in Appendix. The low home preparation group had a higher prevalence of individuals meeting guidelines for riboflavin, folate and calcium, while the high home preparation group saw more participants meeting guidelines for vitamin $\mathrm{A}$, zinc and selenium. There were no significant differences in adherence to fibre guidelines.

Table 5 presents the daily quantity consumed of each of the eight food groups and nutrients that make up the DASH index.

Differences in quantities suggest that the high and low home preparation groups are achieving this measure of high dietary quality through different foods and nutrients. The low home preparation group consumed more fruit and low fat dairy products, but also more sugar and sodium. The high home preparation group consumed more vegetables than their low home preparation counterparts, but also more red and processed meat.

More granular, food-level analysis of participant diets can be found in Table 8 in Appendix. These results mirror those displayed in Table 5: the low home preparation group consumed more low-fat dairy foods such as yoghurt and milk, while the high home preparation group consumed more vegetables. The low home preparation group consumed more whole grain

Table 3 Demographic and socioeconomic characteristics for high and low home preparation groups

\begin{tabular}{|c|c|c|c|c|}
\hline \multirow[t]{2}{*}{ Characteristic } & \multicolumn{4}{|l|}{ High DASH } \\
\hline & High home preparation & Low home preparation & Total & OR/regression coefficient $(95 \% \mathrm{Cl})^{\mathrm{a}, \mathrm{b}}$ \\
\hline$n$ & 621 & 442 & 1063 & \\
\hline \multicolumn{5}{|l|}{ Demographic } \\
\hline Age (mean $(95 \% \mathrm{Cl}))$ & $51.0(49.3,52.6)$ & $54.6(52.7,56.5)$ & $52.4(51.2,53.7)$ & $3.02(0.47,5.57)^{c}$ \\
\hline Sex (\% male) & 39.8 & 45.7 & 42.2 & $0.81(0.58,1.10)$ \\
\hline Ethnicity (\% white) & 76.7 & 90.4 & 82.8 & $0.42(0.25,0.73)$ \\
\hline Children (\% with a child aged $<16$ ) & 31.2 & 23.9 & 28.3 & $0.96(0.62,1.48)$ \\
\hline \multicolumn{5}{|l|}{ Socioeconomic } \\
\hline Education (\% degree) & 41.9 & 34.0 & 38.7 & $0.69(0.48,0.99)$ \\
\hline Equivalised income $(\%>£ 35,000)$ & 33.5 & 39.7 & 36.0 & $1.31(0.90,1.93)$ \\
\hline Occupation (\% professional) & 50.9 & 55.7 & 52.8 & $1.17(0.82,1.68)$ \\
\hline
\end{tabular}

${ }^{a}$ Mutually adjusted for socio-demographic variables excluding the dependent variable: age, sex, ethnicity, children, education, income and occupation

${ }^{b}$ Odds ratios $(95 \% \mathrm{Cl})$, except for in the case of age

'This number represents a regression coefficient $(95 \% \mathrm{Cl})$, as age was analysed as a continuous variable

Note: Italics indicate statistical significance $(p<0.05)$ 
Table 4 Dietary characteristics and prevalence of overweight or obesity for high and low home preparation groups

\begin{tabular}{|c|c|c|c|c|}
\hline \multirow[t]{2}{*}{ Characteristic } & \multicolumn{4}{|l|}{ High DASH } \\
\hline & High home preparation & Low home preparation & Total & Regression coefficient $(95 \% \mathrm{Cl})^{\mathrm{a}}$ \\
\hline \multicolumn{5}{|l|}{ DASH score (Median (IQR)) } \\
\hline & $30(29,32)$ & $30(29,32)$ & $30(29,32)$ & $-0.32(-0.71,0.07)$ \\
\hline \multicolumn{5}{|c|}{$\%$ of total energy from home-prepared food (Mean $(95 \% \mathrm{Cl})$ ) } \\
\hline & $41.8(40.8,42.7)$ & $15.4(14.8,15.9)$ & $31.2(29.9,32.5)$ & $-0.26(-0.27,-0.25)$ \\
\hline \multicolumn{5}{|c|}{ Mean daily energy intake kcal (Mean $(95 \%$ Cl)) } \\
\hline & $1772(1720,1825)$ & $1861(1804,1918)$ & $1808(1769,1847)$ & $45.6(-25.8,117.1)$ \\
\hline \multicolumn{5}{|c|}{ Prevalence of obesity/overweight (\% obese or overweight $\left(\geq 25 \mathrm{~kg} / \mathrm{m}^{2}\right)$ ) } \\
\hline & 52.6 & 55.8 & 53.9 & $1.07(0.78,1.46)$ \\
\hline $\begin{array}{l}\text { Mean daily nutrient intake: } \\
\% \text { meeting guidelines }\end{array}$ & High home preparation & Low home preparation & Total & OR $(95 \% \mathrm{Cl})^{\mathrm{a}}$ \\
\hline Fat $(<35 \%$ energy) & 58.8 & 60.0 & 59.3 & $1.07(0.77,1.49)$ \\
\hline Saturated fat (<11\% energy) & 45.1 & 38.1 & 42.3 & $0.85(0.61,1.18)$ \\
\hline Protein $(45-56 \mathrm{~g})^{\mathrm{b}}$ & 92.4 & 90.8 & 91.8 & $0.53(0.28,1.01)$ \\
\hline Sugar (<11\% energy) & 79.1 & 59.0 & 71.1 & $0.39(0.27,0.55)$ \\
\hline Sodium (< 1600 mg) & 36.0 & 26.3 & 32.1 & $0.71(0.51,1.00)$ \\
\hline Carbohydrate & $49.3(48.4,50.2)$ & $48.5(47.9,49.1)$ & $48.0(47.3,48.7)$ & N/A \\
\hline
\end{tabular}

${ }^{a}$ Mutually adjusted for age, sex, ethnicity, children, education, income and occupation

${ }^{b}$ Dependent on body mass

Note: Italics indicate statistical significance $(p<0.05)$

foods requiring limited preparation, such as wholemeal bread and high fibre breakfast cereals. They also consumed a larger number of sweet things, such as sugar-sweetened beverages, biscuits and chocolates, as well as more crisps and salty snacks, mirrored by the higher levels of sugar and sodium in their diets. The high home preparation group ate more beef and lamb, contributing to a higher overall consumption of red and processed meat. Some results from the food-level analysis were not captured in Table 5, because the DASH index does not take them into account. For example, the high home preparation group also ate more eggs, chicken and fish, while the low home preparation group drank more wine and beer.

\section{Discussion}

\section{Principal findings}

This is the first analysis we are aware of to explore whether substantial consumption of home-prepared food is necessary in order to achieve a high quality diet. We found that it is not: $7 \%$ of adult NDNS participants were in the top tertile for dietary quality as indicated by DASH score, while being in the bottom tertile of proportion of energy derived from home-prepared foods. While all study participants were in the highest tertile of DASH score, there was also no significant difference between the median DASH scores of the high and low home preparation groups, in their energy intakes, nor in the prevalence of overweight or obesity between groups.

Table 5 Daily quantity of each DASH component consumed for high and low home preparation groups (Median (IQR))

\begin{tabular}{|c|c|c|c|c|}
\hline \multirow{2}{*}{$\begin{array}{l}\text { DASH Component } \\
\text { (median (IQR)) }\end{array}$} & \multicolumn{3}{|l|}{ High DASH } & \multirow[b]{2}{*}{ Regression coefficient $(95 \% \mathrm{Cl})^{\mathrm{a}}$} \\
\hline & High home preparation & Low home preparation & Total & \\
\hline Low-fat dairy (g) & $186.9(102.8,283.0)$ & $237.5(143.8,325.6)$ & $207.5(120.0,305.0)$ & $24.6(1.7,47.5)$ \\
\hline Whole grain (g) & $73.8(46.0,125.0)$ & $86.0(53.9,128.0)$ & $78.8(48.8,125.8)$ & $2.2(-6.8,11.2)$ \\
\hline Fruit (g) & $193.8(129.0,297.1)$ & $218.6(138.8,342.5)$ & $201.8(131.9,312.6)$ & $30.81(5.51,56.1)$ \\
\hline Vegetables (g) & $220.0(167.2,295.5)$ & $175.7(123.8,225.4)$ & $195.6(143.7,264.6)$ & $-52.6(-66.7,38.6)$ \\
\hline Nuts \& legumes (g) & $24.1(0.8,52.5)$ & $26.4(3.0,52.5)$ & $24.6(0.9,52.5)$ & $-0.4(-7.7,7.0)$ \\
\hline Sodium (mg) & $1855.4(1469.8,2361.0)$ & $1963.5(1571.4,2436.2)$ & $1908.5(1518.1,2388.2)$ & $107.8(13.8,201.8)$ \\
\hline Sugars (g) & $34.0(20.7,51.8)$ & $44.3(27.9,65.4)$ & $39.5(23.1,57.3)$ & $11.6(7.5,15.6)$ \\
\hline Red \& processed meats (g) & $39.0(10.0,73.8)$ & $28.3(1.5,53.6)$ & $33.0(5.5,65.0)$ & $-10.4(-16.6,-4.3)$ \\
\hline
\end{tabular}

${ }^{a}$ Mutually adjusted for age, sex, ethnicity, children, education, income and occupation Note: Italics indicate statistical significance $(p<0.05)$ 
Relative to their counterparts with a similar dietary quality who relied more heavily on home-prepared food, individuals in the low home preparation group are likely to be older, more likely to be white and less likely to have a degree level education. There are no significant differences in income or occupational grade between the two groups, although both groups were significantly more affluent in terms of education, income and occupation than the NDNS sample as a whole.

\section{Strengths and weaknesses}

From a socio-demographic perspective, the analytic sample used in this study was significantly different to the nationally representative NDNS sample (see Table 3 in Appendix). This was due to the research question, which demanded that only individuals in the top tertile of dietary quality be included. As previous studies have shown, individuals with high dietary quality tend to have certain socio-demographic traits, such as being older and more affluent, $[58,59]$ a pattern which is reflected here.

The positive impact of the DASH diet on hypertension as well as on other chronic diseases has been repeatedly demonstrated, [51, 52] and the DASH index used in this study is in line with that used in epidemiological studies that have reported these associations [51]. As a marker of dietary quality, it is very well-evidenced. However, these studies relate the positive health associations of DASH to 'DASH adherence', defined as the top quintile of a population's DASH score. In this study, a wider definition was used in order to increase sample size, and participants in the top tertile of DASH were defined as having a relatively high dietary quality.

In addition, DASH does not take into account all of the foods that individuals may eat. The fact that some food-level differences are not captured by an examination of DASH score components highlights this. For example, the high home preparation group ate more fish and eggs, while the low home preparation group consumed more wine and beer.

Finally, diet-related disease may be caused by an excess consumption of energy, regardless of dietary quality. However, the DASH score does make food group consumption relative to the overall energetic content of the diet. In addition, the two groups under study did not differ in terms of energy intake.

Food-related measures were derived from food diaries, which were unweighed and self-reported. Some evidence suggests that food diaries are a more accurate measure of dietary intake than other common measures such as food frequency questionnaires [60]. However, misreporting in self-measured dietary instruments is a well-documented limitation, [61] and biomarker analysis of a sub-group of NDNS suggests participants underreport the energy they consume,
[57] which may explain the surprisingly low average calorie intake in participants included in this study (Table 5). While this introduces error, it is not clear whether the two groups under study might misreport in systematically different ways.

This study took a novel approach to quantifying the proportion of home-cooked food in participants' diets. Previous studies and surveys have approached this by asking participants how often they cook, or how often they eat home-prepared or home-cooked foods [62]. These methods are subject to some limitations. The social desirability of cooking and home-cooked food [63] may introduce bias into participant responses to these sorts of questions. In addition, qualitative studies [45] suggest that there is some disagreement among study participants as to what constitutes home-cooked or -prepared food, meaning that the same response may mean different things to different people. While the classification of foods as home-prepared or not used in the current study may be somewhat arbitrary, and is certainly debatable, it has the advantage of being independent of participant interpretations of questions concerning cooking frequency or frequency of preparing meals from scratch.

\section{Implications of the findings}

Previous research has concluded that more frequent consumption of home-prepared food is associated with a higher dietary quality [62]. While this may also be the case in the NDNS sample, the public health community currently lacks an effective method for changing home food preparation practices, as discussed in the introduction. While not discounting the existing work on this subject, it is difficult to see how to move forward with these findings. This study has instead explored individuals who do the unexpected, by eating healthily with minimal energetic contribution from home-prepared foods.

The finding that substantial consumption of homeprepared food is not necessary to achieve high dietary quality suggests that cooking skills interventions and dietary guidelines which emphasise home food preparation as being necessary to a healthy diet may be inappropriate. While home food preparation may be a useful practice for some to achieve greater dietary quality, it does not appear to be a necessary one. Recognising that people can have high quality diets with or without cooking and supporting them to eat healthily regardless seems important.

Examining the dietary composition of the low home preparation group might shed some light on how to support a healthy diet in people who do not eat much home-prepared food. The results of this study suggest that it is their high intake of sugar and sodium which must be addressed. The food-level analysis suggests that this intake may be driven by a higher consumption of 
prepared foods, such as biscuits, chocolate and candy, soft drinks, and crisps and other snacks. Sugar and salt reduction programmes are already under way in the UK, $[64,65]$ as well as globally $[66,67]$. This higher intake of sugar and sodium could be addressed through further reformulation of these prepared foods. In addition, ways of increasing the availability of vegetables requiring little home preparation might be explored, such as increasing the servings of vegetables in prepared meals.

Although their diets are less healthy on some dimensions, most notably in the higher sugar and sodium content of their diet, participants in the low home preparation group are still achieving the same overall dietary quality as indicated by DASH score. This reflects that the DASH score is made up of several evenly weighted components, meaning that a given DASH score could reflect different combinations of healthy and less healthy foods.

Similar scores overall may also reflect the fact that DASH is a relative measure, and that the DASH scores of the participants discussed here were derived from an analysis of the complete adult NDNS sample, which included participants with a lower DASH score whose diets were not analysed in this study (Table 9 in Appendix). Although the low home preparation group were eating more of some 'unhealthy' foods than the high home preparation groups, their quantities were relatively similar in comparison to the quantities of the wider (lower-DASH) sample. This highlights the fact that a diet that is 'healthy' relative to population levels can still include some 'unhealthy' things.

The affluent nature of the analytic sample, which reflects a socioeconomic gradient in diet quality reported by many studies [58, 59] may limit some of the implications that can be drawn from this study. For example, it was noted that there are no significant differences in income between the low home preparation and the high home preparation groups. This might suggest that there is no additional cost involved in eating healthily without much home-prepared food. However, when we note that the analytic sample had a significantly higher prevalence of high-income individuals than the NDNS sample as a whole, it seems plausible that for individuals in the analytic sample cost is not a significant barrier, and dietary practices are driven more by other factors such as time or taste. While it may be possible to eat healthily without eating much home-prepared food, doing so may be more expensive.

\section{Unanswered questions and future research}

We require a better understanding of the conditions necessary to achieve a high quality diet while eating low amounts of home-prepared food. The relatively high socioeconomic position of the analytic sample may mean that this group has more financial resources, or access to a specific array of food outlets due to neighbourhood food environment. Other conditions may also be necessary, such as food and nutrition knowledge, motivation, kitchen facilities, or access to a car. Further research may allow us to understand how practicable the high DASH low home preparation pattern is for the wider population, and what interventions might be carried out to make it practicable for larger numbers.

While cooking skills and practices have been discussed extensively, $[21,45,68]$ eating healthily without relying on home-prepared food may also rely on its own non-cooking set of skills and practices. These could also be an interesting matter for research, although they may be as resistant to change through education interventions as cooking practices appear to be.

The use of food diaries to characterise dietary intake using related concepts such as food 'prepared from scratch' could be further investigated. The way these concepts relate to indices of dietary quality, nutritional intake, socio-demographic characteristics and health outcomes could be analysed.

Finally, a mirror analysis might be carried out which investigates home-prepared food consumption in a sample with low dietary quality.

\section{Conclusion}

This study suggests that consuming a substantial amount of home-prepared food is not necessary to achieve high dietary quality: a set of food practices are present in a sizable proportion of the population which allow individuals to achieve a high dietary quality while relying minimally on home-prepared foods. However, participants included in this study were significantly more affluent than the nationally representative sample from which they were drawn, suggesting thatthe practices in which these individuals engage may be dependent on socioeconomic position. This bears further inquiry.

The low home preparation group consumed more fruit and low-fat dairy products, and less red meat than the high home preparation group, but also more sugar and sodium, highlighting a need for further reduction of sugar and sodium in prepared foods.

The public health community should recognise the existence of a set of food practices which allows individuals to achieve a healthy diet with little contribution from home-prepared food, and make space for it in the design of their policies and interventions. 


\section{Appendix}

Table 6 Demographic and socioeconomic characteristics of analytic sample and rest of NDNS sample

\begin{tabular}{|c|c|c|c|c|c|}
\hline Characteristic & High DASH analytic sample & Rest of sample & Total & Coefficient $(95 \% \mathrm{Cl}) / \mathrm{x}^{2}$ & $p$ value \\
\hline $\mathrm{n}$ & 1063 & 5301 & 6364 & & \\
\hline \multicolumn{6}{|l|}{ Demographic } \\
\hline Age (mean (SD)) & $52.4(51.2,53.7)$ & $47.0(46.3,47.8)$ & $48.0(47.3,48.6)$ & $5.4(4.0,6.8)$ & $<0.01$ \\
\hline Sex (\% male) & 42.2 & 50.0 & 48.6 & 22.8 & $<0.01$ \\
\hline Ethnicity (\% white) & 82.8 & 90.4 & 88.9 & 74.9 & $<0.01$ \\
\hline Children $(\%$ with a child aged $<16$ ) & 28.3 & 32.3 & 31.6 & 18.6 & $<0.01$ \\
\hline \multicolumn{6}{|l|}{ Socioeconomic } \\
\hline Education (\% degree) & 38.7 & 22.6 & 25.5 & 127.4 & $<0.01$ \\
\hline Equivalised income $(\%>£ 35,000)$ & 36.0 & 26.8 & 28.5 & 38.4 & $<0.01$ \\
\hline Occupation (\% professional) & 52.8 & 40.2 & 42.5 & 60.8 & $<0.01$ \\
\hline
\end{tabular}

Note: Italics indicate statistical significance $(p<0.05)$

Table 7 Adherence to nutrient guidelines for high and low home preparation groups

\begin{tabular}{|c|c|c|c|c|c|}
\hline \multirow[t]{2}{*}{ Characteristic } & \multicolumn{4}{|l|}{ High DASH } & \multirow[t]{2}{*}{$p$ value } \\
\hline & High home preparation & Low home preparation & Total & OR $(95 \% \mathrm{Cl})^{\mathrm{a}}$ & \\
\hline \multicolumn{6}{|l|}{ Daily nutrient intake } \\
\hline \multicolumn{6}{|l|}{$\%$ meeting guidelines } \\
\hline Thiamin & 96.5 & 98.0 & 97.1 & $1.4(0.4,4.6)$ & 0.63 \\
\hline Riboflavin & 74.5 & 86.7 & 79.4 & $1.7(1.1,2.7)$ & 0.02 \\
\hline Niacin & 99.9 & 100.0 & 99.9 & N/A & \\
\hline Vitamin B6 & 88.5 & 90.9 & 89.4 & $1.2(0.7,2.2)$ & 0.54 \\
\hline Vitamin B12 & 96.2 & 96.1 & 96.1 & $0.6(0.2,1.6)$ & 0.31 \\
\hline Folate & 78.6 & 89.0 & 82.8 & $2.0(1.2,3.3)$ & $<0.01$ \\
\hline Vitamin C & 94.8 & 95.3 & 95.0 & $1.0(0.5,2.0)$ & 0.98 \\
\hline Vitamin A & 76.8 & 68.9 & 73.7 & $0.6(0.4,0.9)$ & 0.02 \\
\hline Calcium & 63.2 & 77.6 & 69.0 & $1.6(1.1,2.3)$ & 0.01 \\
\hline Phosphorus & 99.7 & 99.8 & 99.7 & $1.2(0.1,12.6)$ & 0.88 \\
\hline Magnesium & 54.6 & 57.3 & 55.7 & $1.0(0.8,1.4)$ & 0.87 \\
\hline Potassium & 28.7 & 36.3 & 31.7 & $1.2(0.8,1.7)$ & 0.42 \\
\hline Iron & 61.9 & 69.5 & 64.9 & $1.0(0.7,1.5)$ & 0.87 \\
\hline Zinc & 64.6 & 58.3 & 62.1 & $0.7(0.5,1.0)$ & 0.03 \\
\hline Selenium & 25.3 & 15.3 & 21.3 & $0.6(0.4,0.8)$ & $<0.01$ \\
\hline lodine & 60.2 & 68.8 & 63.7 & $1.1(0.8,1.6)$ & 0.47 \\
\hline Chloride & 100.0 & 100.0 & 100.0 & $\mathrm{~N} / \mathrm{A}$ & \\
\hline Vitamin E & 28.1 & 27.8 & 27.9 & $1.0(0.7,1.5)$ & 0.80 \\
\hline Copper & 55.2 & 52.0 & 53.9 & $0.8(0.6,1.1)$ & 0.21 \\
\hline Manganese & 97.0 & 98.3 & 97.5 & $1.7(0.5,5.1)$ & 0.38 \\
\hline Biotin & 22.0 & 19.8 & 21.1 & $0.7(0.5,1.1)$ & 0.15 \\
\hline Pantothenic acid & 48.4 & 52.1 & 49.9 & $1.0(0.7,1.3)$ & 0.78 \\
\hline Fibre ( $\geq 30 \mathrm{~g}$ ) & 2.6 & 1.3 & 2.1 & $0.5(0.1,1.7)$ & 0.26 \\
\hline
\end{tabular}

adjusted for age, sex, ethnicity, children, education, income and occupation Note: Italics indicate statistical significance $(p<0.05)$ 
Table 8 Percentage of individuals who eat foods from each food group by level of home-prepared food

\begin{tabular}{|c|c|c|c|c|c|}
\hline \multirow[t]{2}{*}{ Food group } & \multicolumn{3}{|l|}{ High DASH } & \multirow[t]{2}{*}{ OR $(95 \% C l)^{\mathrm{a}}$} & \multirow[t]{2}{*}{$p$-value } \\
\hline & High home preparation & Low home preparation & All & & \\
\hline Reduced fat milk & 83.9 & 94.5 & 88.1 & $2.7(1.5,4.7)$ & $<0.01$ \\
\hline Whole milk & 20.3 & 8.9 & 15.7 & $0.5(0.3,0.7)$ & $<0.01$ \\
\hline Other milk and cream & 42.9 & 32.4 & 38.7 & $0.6(0.4,0.8)$ & $<0.01$ \\
\hline Yogurt, fromage frais and dairy desserts & 56.1 & 65.9 & 60.0 & $1.5(1.1,2.0)$ & 0.02 \\
\hline Butter & 23.1 & 30.0 & 25.8 & $1.6(1.1,2.2)$ & 0.02 \\
\hline Reduced fat spread & 53.2 & 65.6 & 58.2 & $1.6(1.1,2.2)$ & $<0.01$ \\
\hline PUFA margarines and oils & 12.1 & 8.0 & 10.5 & $0.7(0.4,1.3)$ & 0.28 \\
\hline Other margarine, fats and oils & 31.0 & 23.9 & 28.1 & $0.7(0.5,1.0)$ & 0.08 \\
\hline Cheese & 66.1 & 75.4 & 69.8 & $1.4(1.0,2.0)$ & 0.06 \\
\hline Eggs and egg dishes & 71.2 & 55.6 & 65.0 & $0.5(0.3,0.7)$ & $<0.01$ \\
\hline Brown bread & 79.9 & 85.0 & 82.0 & $1.4(1.0,2.2)$ & 0.08 \\
\hline White bread & 59.8 & 65.8 & 62.2 & $1.3(1.0,1.8)$ & 0.09 \\
\hline Other bread & 6.4 & 11.0 & 8.2 & $2.1(1.1,3.7)$ & 0.02 \\
\hline High fibre breakfast cereals & 56.3 & 71.1 & 62.2 & $1.7(1.2,2.3)$ & $<0.01$ \\
\hline Other breakfast cereals & 23.1 & 30.0 & 25.8 & $1.6(1.1,2.2)$ & 0.02 \\
\hline Pasta, rice and other cereals & 45.9 & 48.5 & 46.9 & $0.8(0.6,1.1)$ & 0.26 \\
\hline Nuts and seeds & 48.7 & 45.0 & 47.2 & $0.9(0.6,1.2)$ & 0.44 \\
\hline Salad and other raw vegetables & 93.4 & 91.9 & 92.8 & $0.8(0.5,1.5)$ & 0.55 \\
\hline Vegetables not raw & 100.0 & 98.0 & 99.2 & $\mathrm{~N} / \mathrm{A}$ & \\
\hline Fruit & 98.2 & 98.2 & 98.2 & $0.8(0.3,2.4)$ & 0.70 \\
\hline Fruit juice & 51.9 & 53.1 & 52.4 & $1.2(0.8,1.6)$ & 0.36 \\
\hline Smoothies $100 \%$ fruit and/or juice & 1.7 & 2.0 & 1.9 & $1.4(0.4,4.7)$ & 0.56 \\
\hline Biscuits, chocolate and candy & 74.8 & 84.0 & 78.3 & $1.7(1.2,2.6)$ & $<0.01$ \\
\hline Ice cream & 16.9 & 27.0 & 21.0 & $1.8(1.2,2.6)$ & $<0.01$ \\
\hline Puddings & 22.1 & 20.8 & 21.6 & $0.8(0.6,1.2)$ & 0.37 \\
\hline Buns, cakes, pastries and fruit pies & 47.2 & 64.1 & 53.9 & $1.9(1.3,2.6)$ & $<0.01$ \\
\hline Sugars, preserves and sweet spreads & 75.8 & 70.5 & 73.7 & $0.8(0.6,1.2)$ & 0.25 \\
\hline Crisps and savoury snacks & 29.4 & 39.4 & 33.4 & $1.6(1.2,2.2)$ & $<0.01$ \\
\hline Oily fish & 42.9 & 36.8 & 40.5 & $0.6(0.5,0.9)$ & 0.01 \\
\hline White fish breaded or fried & 14.8 & 20.6 & 17.1 & $1.4(1.0,2.1)$ & 0.07 \\
\hline Other fish dishes (incl. White fish and shellfish) & 46.2 & 46.8 & 46.4 & $0.9(0.7,1.3)$ & 0.65 \\
\hline Bacon and ham & 3.8 & 6.0 & 4.7 & $2.2(1.1,4.4)$ & 0.03 \\
\hline Pork and dishes & 13.9 & 24.4 & 18.1 & $1.8(1.2,2.6)$ & $<0.01$ \\
\hline Sausages & 18.7 & 19.4 & 19.0 & $0.9(0.6,1.4)$ & 0.78 \\
\hline Beef, veal and dishes & 43.8 & 33.2 & 39.5 & $0.6(0.4,0.8)$ & $<0.01$ \\
\hline Lamb and dishes & 16.4 & 11.4 & 14.4 & $0.7(0.5,1.1)$ & 0.17 \\
\hline Liver and dishes & 6.4 & 7.7 & 6.9 & $1.1(0.6,2.1)$ & 0.77 \\
\hline Chicken and turkey dishes & 66.1 & 62.2 & 64.5 & $0.8(0.6,1.2)$ & 0.31 \\
\hline Coated chicken & 3.8 & 6.0 & 4.7 & $2.2(1.1,4.4)$ & 0.03 \\
\hline Burgers and kebabs & 4.7 & 4.9 & 4.8 & $1.0(0.4,2.1)$ & 0.90 \\
\hline Meat pies and pastries & 5.9 & 14.3 & 9.3 & $2.4(1.4,4.1)$ & $<0.01$ \\
\hline Other meat and meat products & 45.9 & 48.5 & 46.9 & $0.8(0.6,1.1)$ & 0.26 \\
\hline Chips, roasted and fried potatoes & 42.7 & 49.9 & 45.6 & $1.3(0.9,1.7)$ & 0.14 \\
\hline
\end{tabular}


Table 8 Percentage of individuals who eat foods from each food group by level of home-prepared food (Continued)

\begin{tabular}{|c|c|c|c|c|c|}
\hline \multirow[t]{2}{*}{ Food group } & \multicolumn{3}{|l|}{ High DASH } & \multirow[t]{2}{*}{ OR $(95 \% \mathrm{Cl})^{\mathrm{a}}$} & \multirow[t]{2}{*}{$p$-value } \\
\hline & High home preparation & Low home preparation & All & & \\
\hline Other potato dishes & 76.4 & 84.6 & 79.7 & $1.4(0.9,2.2)$ & 0.13 \\
\hline Artificial sweeteners & 11.1 & 15.6 & 12.9 & $1.4(0.9,2.1)$ & 0.14 \\
\hline Dietary supplements & 36.8 & 40.7 & 38.4 & $1.1(0.8,1.5)$ & 0.67 \\
\hline Tea, coffee and water & 100.0 & 99.5 & 99.8 & N/A & \\
\hline Soft drinks low calorie & 24.5 & 33.4 & 28.0 & $1.6(1.1,2.4)$ & 0.01 \\
\hline Soft drinks not low calorie & 24.0 & 38.1 & 29.6 & $2.0(1.4,2.9)$ & $<0.01$ \\
\hline Beer, lager, cider and perry & 22.0 & 27.5 & 24.2 & $1.2(0.8,1.8)$ & 0.27 \\
\hline Wine & 43.0 & 43.6 & 43.2 & $0.8(0.6,1.2)$ & 0.32 \\
\hline Spirits and liqueurs & 9.3 & 16.0 & 12.0 & $1.5(0.9,2.5)$ & 0.13 \\
\hline Miscellaneous & 98.2 & 94.2 & 96.6 & $0.3(0.1,0.7)$ & $<0.01$ \\
\hline
\end{tabular}

${ }^{a}$ Adjusted for age, sex, ethnicity, children, education, income and occupation Note: Italics indicate statistical significance $(p<0.05)$

Table 9 Median (IQR) grams of food eaten daily by high-DASH consumers of those foods

\begin{tabular}{|c|c|c|c|c|c|}
\hline \multirow[t]{2}{*}{ Food group } & \multicolumn{3}{|l|}{ High DASH } & \multirow[t]{2}{*}{ Coefficient $(95 \% \mathrm{Cl})^{\mathrm{a}}$} & \multirow[t]{2}{*}{$p$-value } \\
\hline & $\begin{array}{l}\text { High home } \\
\text { preparation }\end{array}$ & $\begin{array}{l}\text { Low home } \\
\text { preparation }\end{array}$ & All & & \\
\hline Reduced fat milk & $172.5(88.1,253.5)$ & $190.0(105.0,292.5)$ & $178.8(96.3,267.5)$ & $12.4(-10.0,34.9)$ & 0.28 \\
\hline Whole milk & $52.5(9.5,159.2)$ & $25.0(10.0,149.3)$ & $50.0(9.5,159.2)$ & $-5.9(-13.6,1.8)$ & 0.13 \\
\hline Other milk and cream & $21.0(9.6,62.5)$ & $12.4(7.5,30.0)$ & $16.3(7.5,48.8)$ & $-16.7(-36.2,2.7)$ & 0.09 \\
\hline Yogurt, fromage frais and dairy desserts & $60.0(31.3,93.8)$ & $68.1(43.8,100.0)$ & $62.5(32.5,100.0)$ & $13.1(3.0,23.3)$ & 0.01 \\
\hline Butter & $15.0(7.5,27.5)$ & $20.0(10.0,30.0)$ & $15.0(9.0,30.0)$ & $2.6(-1.4,6.7)$ & 0.20 \\
\hline Reduced fat spread & $8.5(4.3,14.6)$ & $11.2(6.8,17.0)$ & $10.0(5.0,16.3)$ & $2.1(0.9,3.4)$ & $<0.01$ \\
\hline PUFA margarines and oils & $1.9(0.7,7.8)$ & $1.4(0.4,2.5)$ & $1.5(0.7,4.5)$ & $-1.3(-3.1,0.5)$ & 0.16 \\
\hline Other margarine, fats and oils & $2.9(1.5,6.2)$ & $1.4(0.7,3.0)$ & $2.6(1.1,4.8)$ & $-1.4(-2.3,-0.5)$ & $<0.01$ \\
\hline Cheese & $18.3(10.0,30.6)$ & $18.8(10.0,32.3)$ & $18.5(10.0,31.3)$ & $0.2(-2.7,3.0)$ & 0.91 \\
\hline Eggs and egg dishes & $30.0(15.0,45.0)$ & $28.5(14.3,44.3)$ & $28.5(15.0,45.0)$ & $-4.8(-8.7,-1.0)$ & 0.01 \\
\hline Brown bread & $49.7(27.6,72.6)$ & $59.2(33.5,89.5)$ & $52.2(30.0,82.5)$ & $10.4(5.3,15.4)$ & $<0.01$ \\
\hline White bread & $30.3(18.0,52.8)$ & $36.0(20.0,73.0)$ & $32.4(18.7,61.9)$ & $10.5(4.8,16.2)$ & $<0.01$ \\
\hline Other bread & $24.5(14.8,38.6)$ & $29.3(20.6,43.0)$ & $25.9(20.0,38.8)$ & $7.9(-4.9,20.7)$ & 0.23 \\
\hline High fibre breakfast cereals & $29.3(15.0,54.0)$ & $36.6(20.0,66.0)$ & $32.5(17.5,59.4)$ & $3.2(-4.4,10.7)$ & 0.41 \\
\hline Other breakfast cereals & $15.0(7.5,27.5)$ & $20.0(10.0,30.0)$ & $15.0(9.0,30.0)$ & $2.6(-1.4,6.7)$ & 0.20 \\
\hline Pasta, rice and other cereals & $12.5(6.3,25.8)$ & $12.5(5.8,24.8)$ & $12.5(6.3,25.0)$ & $-1.3(-3.7,1.2)$ & 0.32 \\
\hline Nuts and seeds & $12.5(5.6,25.0)$ & $9.7(6.3,20.9)$ & $12.5(5.9,24.5)$ & $-0.9(-5.9,4.2)$ & 0.74 \\
\hline Salad and other raw vegetables & $56.4(24.3,94.6)$ & $63.6(27.0,103.4)$ & $60.1(26.3,98.6)$ & $6.7(-1.3,14.6)$ & 0.10 \\
\hline Vegetables not raw & $190.2(131.9,259.4)$ & $139.2(95.0,183.3)$ & $163.1(116.3,232.3)$ & $-52.3(-63.7,-40.9)$ & $<0.01$ \\
\hline Fruit & $196.0(132.2,301.3)$ & $219.4(145.2,348.8)$ & $203.9(134.9,314.6)$ & $7.5(-8.0,23.0)$ & 0.34 \\
\hline Fruit juice & $77.5(31.3,150.0)$ & $112.5(50.0,175.0)$ & $93.8(37.5,150.0)$ & $32.3(14.5,50.2)$ & $<0.01$ \\
\hline Smoothies $100 \%$ fruit and/or juice & $66.3(66.3,198.8)$ & $66.3(43.5,95.4)$ & $66.3(66.3,95.4)$ & $23.0(-119.7,165.7)$ & 0.73 \\
\hline Biscuits, chocolate and candy & $14.8(8.1,25.0)$ & $20.4(10.0,40.0)$ & $17.5(8.8,32.8)$ & $11.3(8.0,14.6)$ & $<0.01$ \\
\hline Ice cream & $30.0(21.3,50.0)$ & $27.5(16.3,50.0)$ & $30.0(20.0,50.0)$ & $0.5(-4.6,5.5)$ & 0.85 \\
\hline Puddings & $35.5(22.5,53.1)$ & $27.5(16.9,50.0)$ & $30.0(20.0,50.0)$ & $-0.8(-11.2,9.7)$ & 0.89 \\
\hline Buns, cakes, pastries and fruit pies & $24.0(14.0,41.3)$ & $30.0(15.8,54.5)$ & $27.5(15.0,48.0)$ & $5.8(1.9,9.7)$ & $<0.01$ \\
\hline Sugars, preserves and sweet spreads & $12.0(5.4,20.2)$ & $9.0(3.8,16.9)$ & $11.0(5.0,19.6)$ & $-0.3(-2.2,1.7)$ & 0.78 \\
\hline
\end{tabular}


Table 9 Median (IQR) grams of food eaten daily by high-DASH consumers of those foods (Continued)

\begin{tabular}{|c|c|c|c|c|c|}
\hline \multirow[t]{2}{*}{ Food group } & \multicolumn{3}{|l|}{ High DASH } & \multirow[t]{2}{*}{ Coefficient $(95 \% \mathrm{Cl})^{\mathrm{a}}$} & \multirow[t]{2}{*}{$p$-value } \\
\hline & $\begin{array}{l}\text { High home } \\
\text { preparation }\end{array}$ & $\begin{array}{l}\text { Low home } \\
\text { preparation }\end{array}$ & All & & \\
\hline Crisps and savoury snacks & $8.1(6.3,13.8)$ & $12.5(6.3,18.8)$ & $9.0(6.3,17.3)$ & $3.0(0.9,5.1)$ & $<0.01$ \\
\hline Oily fish & $37.5(25.0,53.0)$ & $28.1(16.5,40.0)$ & $32.3(22.3,50.5)$ & $-4.2(-9.7,1.4)$ & 0.14 \\
\hline White fish breaded or fried & $30.0(25.0,50.0)$ & $28.0(25.0,37.5)$ & $30.0(25.0,45.0)$ & $-6.2(-12.3,-0.1)$ & 0.05 \\
\hline $\begin{array}{l}\text { Other fish dishes (incl. White fish and } \\
\text { shellfish) }\end{array}$ & $30.0(18.0,49.0)$ & $28.8(15.0,43.3)$ & $30.0(16.3,45.0)$ & $-3.9(-9.4,1.5)$ & 0.16 \\
\hline Bacon and ham & $25.0(15.0,48.8)$ & $23.8(11.3,31.3)$ & $23.8(11.3,32.5)$ & $1.4(-13.7,16.5)$ & 0.85 \\
\hline Pork and dishes & $30.0(22.5,45.0)$ & $30.0(21.3,42.8)$ & $30.0(22.3,42.8)$ & $1.6(-3.7,6.9)$ & 0.55 \\
\hline Sausages & $28.4(15.0,38.0)$ & $22.5(15.0,39.9)$ & $26.2(15.0,39.9)$ & $-3.6(-9.2,2.0)$ & 0.21 \\
\hline Beef, veal and dishes & $34.7(23.4,53.3)$ & $29.2(17.5,39.8)$ & $32.0(21.0,50.0)$ & $-4.1(-10.4,2.1)$ & 0.19 \\
\hline Lamb and dishes & $40.0(25.9,54.2)$ & $23.5(19.3,36.5)$ & $35.0(22.5,47.9)$ & $-15.5(-26.8,-4.3)$ & $<0.01$ \\
\hline Liver and dishes & $20.0(10.0,33.2)$ & $20.0(13.8,25.6)$ & $20.0(12.5,30.0)$ & $1.2(-5.1,7.6)$ & 0.70 \\
\hline Chicken and turkey dishes & $56.2(32.5,83.4)$ & $40.5(26.3,65.0)$ & $48.8(30.0,77.5)$ & $-11.3(-18.3,-4.3)$ & $<0.01$ \\
\hline Coated chicken & $100.0(60.0,195.0)$ & $95.0(45.0,125.0)$ & $95.0(45.0,130.0)$ & $6.0(-51.4,63.3)$ & 0.84 \\
\hline Burgers and kebabs & $25.0(15.0,53.8)$ & $37.5(8.5,46.9)$ & $25.0(10.0,50.0)$ & $3.6(-9.5,16.7)$ & 0.58 \\
\hline Meat pies and pastries & $30.0(22.5,50.0)$ & $37.5(30.0,45.8)$ & $35.0(25.0,45.8)$ & $0.5(-9.4,10.3)$ & 0.92 \\
\hline Other meat and meat products & $12.5(6.3,25.8)$ & $12.5(5.8,24.8)$ & $12.5(6.3,25.0)$ & $-1.3(-3.7,1.2)$ & 0.32 \\
\hline Chips, roasted and fried potatoes & $46.0(25.4,64.4)$ & $41.3(25.0,66.3)$ & $41.3(25.0,64.4)$ & $-1.4(-6.8,4.1)$ & 0.63 \\
\hline Other potato dishes & $60.0(40.0,93.3)$ & $65.3(42.5,110.0)$ & $62.5(40.5,101.8)$ & $10.3(2.6,18.1)$ & $<0.01$ \\
\hline Artificial sweeteners & $1.0(0.5,2.6)$ & $3.0(0.9,4.8)$ & $1.5(0.5,3.8)$ & $0.8(-0.4,2.0)$ & 0.18 \\
\hline Dietary supplements & $1.5(1.0,3.0)$ & $2.0(1.0,3.0)$ & $1.5(1.0,3.0)$ & $-0.8(-2.3,0.6)$ & 0.25 \\
\hline Tea, coffee and water & $1288.4(952.7,1625.5)$ & $1248.9(899.3,1635.5)$ & $\begin{array}{l}1264.3(930.5 \\
1630.8)\end{array}$ & $15.3(-64.1,94.7)$ & 0.71 \\
\hline Soft drinks low calorie & $150.0(82.5,300.0)$ & $142.0(75.0,325.0)$ & $142.0(75.0,300.0)$ & $6.7(-96.1,109.4)$ & 0.90 \\
\hline Soft drinks not low calorie & $100.0(62.5,160.8)$ & $85.0(50.0,187.5)$ & $91.8(50.0,175.0)$ & $-15.2(-53.0,22.5)$ & 0.43 \\
\hline Beer, lager, cider and perry & $165.0(75.0,322.9)$ & $310.0(141.8,496.1)$ & $225.0(110.0,425.3)$ & $176.3(85.1,267.5)$ & $<0.01$ \\
\hline Wine & $102.1(43.8,170.0)$ & $129.0(62.5,218.8)$ & $118.8(46.9,187.5)$ & $27.1(2.4,51.7)$ & 0.03 \\
\hline Spirits and liqueurs & $21.0(6.5,25.9)$ & $22.5(11.5,28.8)$ & $22.5(8.6,28.8)$ & $1.4(-4.7,7.5)$ & 0.65 \\
\hline Miscellaneous & $35.8(14.0,77.3)$ & $34.3(13.4,81.3)$ & $34.8(13.8,78.8)$ & $-1.0(-8.3,6.2)$ & 0.78 \\
\hline
\end{tabular}

adjusted for age, sex, ethnicity, children, education, income and occupation Note: Italics indicate statistical significance $(p<0.05)$

Table 10 Median DASH scores in complete sample and analytic subsample

\begin{tabular}{lll}
\hline Sample & Participants (n) & DASH score (median (IQR)) \\
\hline Complete NDNS adult sample & 6364 & $24(20,28)$ \\
Analytic subsample & 1063 & $30(29,32)$ \\
\hline
\end{tabular}




\section{Acknowledgements}

Not applicable.

\section{Funding}

CCA, TLP and JA are funded by the Centre for Diet and Activity Research (CEDAR), a UKCRC Public Health Research Centre of Excellence. Funding from the British Heart Foundation, Cancer Research UK, Economic and Social Research Council, Medical Research Council, the National Institute for Health Research, and the Wellcome Trust, under the auspices of the UK Clinical Research Collaboration, is gratefully acknowledged.

\section{Availability of data and materials}

The datasets supporting the conclusions of this article are available in the UK Data Service repository, https://doi.org/10.5255/UKDA-SN-6533-8 https:// discover.ukdataservice.ac.uk/catalogue/?sn=6533.

\section{Authors' contributions}

All authors conceived of the study and developed the methods. CCA prepared the data with help from TLP. CCA conducted the statistical analyses and drafted the manuscript. All authors contributed significantly to revisions and have read and approved the final manuscript.

\section{Ethics approval and consent to participate}

Ethics approval for NDNS was obtained from the Oxfordshire Research Ethics Committee. No further ethical approval was required for the secondary analysis of anonymised data which is presented here.

\section{Consent for publication}

Not applicable

\section{Competing interests}

The authors declare that they have no competing interests and no financial disclosures to make.

\section{Publisher's Note}

Springer Nature remains neutral with regard to jurisdictional claims in published maps and institutional affiliations.

\section{Received: 3 August 2018 Accepted: 3 January 2019}

Published online: 17 January 2019

\section{References}

1. Lock K, Pomerleau J, Causer L, Altmann DR, McKee M. The global burden of disease attributable to low consumption of fruit and vegetables: implications for the global strategy on diet. Bull World Health Organ. 2005; 83:100-8.

2. Mytton OT, Nnoaham K, Eyles H, Scarborough P, Mhurchu CN. Systematic review and meta-analysis of the effect of increased vegetable and fruit consumption on body weight and energy intake. BMC Public Health. 2014 14:886.

3. Schwingshackl L, Hoffmann G, Kalle-Uhlmann T, Arregui M, Buijsse B, Boeing $H$. Fruit and vegetable consumption and changes in anthropometric variables in adult populations: a systematic review and meta-analysis of prospective cohort studies. PLoS One. 2015:10:e0140846.

4. Wang X, Ouyang Y, Liu J, Zhu M, Zhao G, Bao W, et al. Fruit and vegetable consumption and mortality from all causes, cardiovascular disease, and cancer: systematic review and dose-response meta-analysis of prospective cohort studies. Br Med J. 2014:349:94490.

5. Liu S, Manson JE, Lee IM, Cole SR, Hennekens CH, Willett WC, et al. Fruit and vegetable intake and risk of cardiovascular disease: the Women's health study. Am J Clin Nutr. 2000;72:922-8.

6. Crowe FL, Roddam AW, Key TJ, Appleby PN, Overvad K, Jakobsen MU, et al. Fruit and vegetable intake and mortality from ischaemic heart disease: results from the European prospective investigation into Cancer and nutrition (EPIC)-heart study, Eur Heart J. 2011:32:1235-43.

7. Guthrie JF, Lin B-H, Frazao E. Role of food prepared away from home in the American diet, 1977-78 versus 1994-96: changes and consequences. J Nutr Educ Behav. 2002;34:140-50.

8. Lin $\mathrm{BH}$, Frazao EGJ. Away-from-home foods increasingly important to quality of American diet. J Interf Cytokine Res. 1999;24:1-22.
9. Möser A. Food preparation patterns in German family households. An econometric approach with time budget data. Appetite. 2010:55:99-107.

10. Smith LP, Ng SW, Popkin BM, Croll J, Perry C, Wethington E, et al. Trends in US home food preparation and consumption: analysis of national nutrition surveys and time use studies from 1965-1966 to 2007-2008. Nutr J. 2013;12:316-20.

11. Taillie LS. Who's cooking? Trends in US home food preparation by gender, education, and race/ethnicity from 2003 to 2016. Nutr J. 2018;17:41.

12. Bowman SA, Vinyard BT. Fast food consumption of U.S. adults: impact on energy and nutrient intakes and overweight status. J Am Coll Nutr. 2004;23: 163-8.

13. Lachat C, Nago E, Verstraeten R, Roberfroid D, Van Camp J, Kolsteren P. Eating out of home and its association with dietary intake: a systematic review of the evidence. Obes Rev. 2012:13:329-46.

14. Nguyen B, Powell $L$. The impact of restaurant consumption among US adults: effects on energy and nutrient intakes. Public Health Nutr. 2014; 17(11):2445-52.

15. Wolfson JA, Bleich SN, Shao Q, Chin K-V, McGuire S, Ayala GX, et al. Is cooking at home associated with better diet quality or weight-loss intention? Public Health Nutr. 2015:18:1397-406.

16. Larson NI, Perry CL, Story M, Neumark-Sztainer D. Food preparation by young adults is associated with better diet quality. J Am Diet Assoc. 2006; 106:2001-7.

17. Smith KJ, McNaughton SA, Gall SL, Blizzard L, Dwyer T, Venn AJ. Involvement of young Australian adults in meal preparation: cross-sectional associations with sociodemographic factors and diet quality. J Am Diet Assoc. 2010:110:1363-7.

18. Chen RC-Y, Lee M-S, Chang Y-H, Wahlqvist ML. Cooking frequency may enhance survival in Taiwanese elderly. Public Health Nutr. 2012;15:1142-9.

19. Zong G, Eisenberg DM, Hu FB, Sun Q, Zhang J. Consumption of meals prepared at home and risk of type 2 diabetes: an analysis of two prospective cohort studies. PLoS Med. 2016;13:e1002052.

20. Mills S, Brown H, Wrieden W, White M, Adams J. Frequency of eating home cooked meals and potential benefits for diet and health: cross-sectional analysis of a population- based cohort study. Int J Behav Nutr Phys Act. 2017;14(1):109.

21. Short F. Domestic cooking skills - what are they? J Home Econ Inst Aust. 2003;10:13-22.

22. Michaud P, Condrasky M, Griffin SF. Review and application of current literature related to culinary programs for nutrition educators. Top Clin Nutr. 2007;22:336-48

23. Condrasky MD, Hegler M. How culinary nutrition can save the health of a nation. J Ext. 2010:48:1-6.

24. Lichtenstein AH, Ludwig DS. Bring back home economics education. JAMA. 2010;303:1857-8.

25. Ministry of Health of Brazil, Secretariat of Health Care, Primary Health Care Department. Dietary Guidelines for the Brazilian population. Brasilia: Ministry of Health Brazil; 2015. http://bvsms.saude.gov.br/bvs/publicacoes/dietary_ guidelines_brazilian_population.pdf. Accessed 30 May 2018

26. Food-based dietary guidelines - Japan. Food and Agriculture Organization of the United Nations. http://www.fao.org/nutrition/education/food-dietaryguidelines/regions/japan/en/. Accessed 30 May 2018.

27. Canadian Food Guide Consultation. Guiding principles. Food Guide Consultation https://www.foodguideconsultation.ca/guiding-principlesdetailed. Accessed 30 May 2018.

28. Rees R, Hinds K, Dickson K, Thomas J. Communities that cook. A systematic review of the effectiveness and appropriateness of interventions to introduce adults to home cooking; 2012.

29. Begley A, Gallegos D, Vidgen $H$. Effectiveness of Australian cooking skill interventions. Br Food J. 2017;119:973-91.

30. Reicks M, Kocher M, Reeder J. Impact of Cooking and Home Food Preparation Interventions Among Adults: A Systematic Review (2011-2016). J Nutr Educ Behav. 2018:50:148-72 e1.

31. Appelhans BM, Segawa E, Janssen I, Nackers LM, Kazlauskaite R, Baylin A et al. Meal preparation and cleanup time and cardiometabolic risk over 14years in the study of Women's health across the nation (SWAN). Prev Med. 2015;71:1-6.

32. Howard S, Adams J, White M. Nutritional content of supermarket ready meals and recipes by television chefs in the United Kingdom: cross sectional study. BMJ. 2012;345:e7607.

33. Pope L, Latimer L, Wansink B. Viewers vs, doers. The relationship between watching food television and BMI. Appetite. 2015;90:131-5. 
34. Jones M, Freeth E. A systematic cross-sectional analysis of British based celebrity chefs' recipes: is there cause for public health concern? Food Public Health. 2013;3:100-10.

35. Naruseviciute G, Whybrow S, Macdiarmid JI, McNeill G. Is "home cooked" healthier and cheaper than ready meals? Proc Nutr Soc. 2015;74:E90.

36. Guides alimentaires du programme national nutrition-santé. La santé vient en mangeant: le guide alimentaire pour tous. Saint-Yrieix-la-Perche: Programme national nutrition-santé; 2002. http://www.mangerbouger.fr/content/ download/3812/101709/version/5/file/581.pdf. Accessed 30 May 2018.

37. Discover - National Diet and Nutrition Survey Years 1-8, 2008/09-2015/16 https://discover.ukdataservice.ac.uk/catalogue/?sn=6533\&type= Data\%20catalogue. Accessed 30 May 2018.

38. Lachat C, Hawwash D, Ocké MC, Berg C, Forsum E, Hörnell A, et al. Strengthening the reporting of observational studies in epidemiology nutritional epidemiology (STROBE-nut): an extension of the STROBE statement. Nutr Bull. 2016;41:240-51.

39. Bates B, Cox L, Nicholson S, Page P, Prentice A, Steer T, et al. National Diet and nutrition survey results from years 5 and 6 (combined) of the rolling Programme (2012/2013-2013/2014). London: Public Health England; 2017. https://assets.publishing.service.gov.uk/government/uploads/system/ uploads/attachment_data/file/551352/NDNS_Y5_6_UK_Main_Text.pdf. Accessed 30 May 2018

40. Roberts C, Steer T, Maplethorpe N, Cox L, Meadows S, Nicholson S, et al. National Diet and nutrition survey results from years 7 and 8 (combined) of the rolling Programme (2014/2015-2015/2016). London: Public Health England; 2018. https://assets.publishing.service.gov.uk/government/uploads/ system/uploads/attachment_data/file/699241/NDNS_results_years_7_and_8. pdf. Accessed 6 Jun 2018

41. Bates B, Lennox A, Prentice A, Bates C, Page P, Nicholson S, et al. National Diet and nutrition survey results from years 1, 2, 3 and 4 (combined) of the rolling Programme (2008/2009-2011/2012). London: Public Health England; 2017. https://assets.publishing.service.gov.uk/government/uploads/system/ uploads/attachment_data/file/594361/NDNS_Y1_to_4_UK_report_full_text_ revised_February 2017.pdf. Accessed 30 May 2018

42. Lennox A, Fitt E, Whitton C, Roberts C, Prynne C. Appendix a: dietary data collection and editing. London: Public Health England; 2014. https://www. food.gov.uk/sites/default/files/media/document/ndns-appendix-a.pdf. Accessed 8 Mar 2018

43. Engler-Stringer R. Food, cooking skills, and health: a literature review. Can J Diet Pract Res. 2010;71:141-5.

44. Wolfson JA, Smith KC, Frattaroli S, Bleich SN. Public perceptions of cooking and the implications for cooking behaviour in the USA. Public Health Nutr. 2016;19:1606-15.

45. Wolfson JA, Bleich SN, Smith KC, Frattaroli S. What does cooking mean to you?: perceptions of cooking and factors related to cooking behavior Appetite. 2016;97:146-54

46. Méjean C, Lampuré A, Si Hassen W, Gojard S, Péneau S, Hercberg S, et al. Influence of food preparation behaviors on 5-year weight change and obesity risk in a French prospective cohort. Int J Behav Nutr Phys Act. 2018;15:120.

47. Short F. Domestic cooking practices and cooking skills: findings from an English study*. Food Serv Technol. 2003;3:177-85.

48. Stead M, Caraher M, Wrieden W, Longbottom P, Valentine K, Anderson A. Confident, fearful and hopeless cooks: findings from the development of a food-skills initiative. Br Food J. 2004;106:274-87.

49. McGowan L, Caraher M, Raats M, Lavelle F, Hollywood L, McDowell D, et al. Domestic cooking and food skills: a review. Crit Rev Food Sci Nutr. 2017;57: 2412-31.

50. Penney TL, Jones NRV, Adams J, Maguire ER, Burgoine T, Monsivais P. Utilization of away-from-home food establishments, dietary approaches to stop hypertension dietary pattern, and obesity. Am J Prev Med. 2017;53: e155-63.

51. Fung TT, Chiuve SE, McCullough ML, Rexrode KM, Logroscino G, Hu FB. Adherence to a DASH-style diet and risk of coronary heart disease and stroke in women. Arch Intern Med. 2008;168:713-20.

52. Sacks FM, Svetkey LP, Vollmer WM, Appel LJ, Bray GA, Harsha D, et al. Effects on blood pressure of reduced dietary sodium and the dietary approaches to stop hypertension (DASH) diet. N Engl J Med. 2001;344:3-10.

53. Population Health Division. Technical guidance on nutrition labelling. Guidance. London: Department of Health; 2016. https://assets.publishing. service.gov.uk/government/uploads/system/uploads/attachment_data/file/ 595961/Nutrition_Technical_Guidance.pdf. Accessed 31 May 2018
54. Committee on Medical Aspects. Dietary Reference Values (DRVs) for Food Energy and Nutrients for the UK. 1991.

55. Scientific Advisory Committee on Nutrition. Salt and Health: Food Standards Agency; Department of Health. Norwich: The Stationery Office; 2003.

56. Scientific Advisory Committee on Health (SACN). Carbohydrates and Health. London: The Stationery Office; 2015.

57. Lennox A, Bluck L, Page P, Pell D, Cole D, Ziaudden N, et al. Appendix X: misreporting in the National Diet and nutrition survey rolling Programme (NDNS RP): summary of results and their interpretation. London: Public Health England; 2017. https://www.food.gov.uk/sites/default/files/media/ document/ndns-appendix-x.pdf. Accessed 1 Jun 2018

58. Galobardes B, Morabia A, Bernstein MS. Diet and socioeconomic position: does the use of different indicators matter? Int J Epidemiol. 2001;30:334-40.

59. Mullie P, Clarys P, Hulens M, Vansant G. Dietary patterns and socioeconomic position. Eur J Clin Nutr. 2010;64:231-8.

60. Day NE, McKeown N, Wong MY, Welch A, Bingham S. Epidemiological assessment of diet: a comparison of a 7-day diary with a food frequency questionnaire using urinary markers of nitrogen, potassium and sodium. Int J Epidemiol. 2001;30:309-17.

61. Archer E, Hand GA, Blair SN. Validity of U.S. Nutritional Surveillance: National Health and Nutrition Examination Survey Caloric Energy Intake Data, 19712010. PLOS ONE. 2013:8:e76632.

62. Mills S, White M, Brown H, Wrieden W, Kwasnicka D, Halligan J, et al. Health and social determinants and outcomes of home cooking: a systematic review of observational studies. Appetite. 2017;111:116-34.

63. Mills S, White M, Wrieden W, Brown H, Stead M, Adams J. Home food preparation practices, experiences and perceptions: a qualitative interview study with photo-elicitation. PLoS One. 2017;12. https://doi.org/10.1371/ journal.pone.0182842.

64. Soft Drinks Industry Levy. GOV.UK. https://www.gov.uk/government/publications/ soft-drinks-industry-levy/soft-drinks-industry-levy. Accessed 1 Jun 2018

65. He FJ, Brinsden HC, MacGregor GA. Salt reduction in the United Kingdom: a successful experiment in public health. J Hum Hypertens. 2014:28:345-52.

66. Cabrera Escobar MA, Veerman JL, Tollman SM, Bertram MY, Hofman KJ. Evidence that a tax on sugar sweetened beverages reduces the obesity rate: a meta-analysis. BMC Public Health. 2013;13:1072.

67. He FJ, MacGregor GA. A comprehensive review on salt and health and current experience of worldwide salt reduction programmes. J Hum Hypertens. 2009;23:363-84.

68. Caraher DM, Lang T. Can't cook, won't cook: a review of cooking skills and their relevance to health promotion. Int J Health Promot Educ. 1999:37:89-100.

\section{Ready to submit your research? Choose BMC and benefit from:}

- fast, convenient online submission

- thorough peer review by experienced researchers in your field

- rapid publication on acceptance

- support for research data, including large and complex data types

- gold Open Access which fosters wider collaboration and increased citations

- maximum visibility for your research: over $100 \mathrm{M}$ website views per year

At $\mathrm{BMC}$, research is always in progress.

Learn more biomedcentral.com/submission 